\title{
A STUDY TO ASSESS THE QUALITY OF LIFE AFTER MASTECTOMY AMONG WOMEN IN A TERTIARY CARE HOSPITAL, KARAD
}

\author{
Trupti S. Bhosale1, Mahadeo Shinde2, Ruksar Patel ${ }^{3}$, Reshma Nair 4
}

1Statistician, Directorate of Research, Krishna Institute of Medical Sciences, Deemed to be University, Karad, Maharashtra, India. 2Professor, Department of Medical Nursing, Krishna Institute of Nursing Sciences, KIMSDU, Karad, Maharashtra, India. 3 Student, Krishna Institute of Nursing Sciences, Karad, Maharashtra, India. ${ }^{4}$ Student, Krishna Institute of Nursing Sciences, Karad, Maharashtra, India.

\section{BACKGROUND}

ABSTRACT

Breast cancer is the most common cancer in women. Surgical treatment is the most common treatment of breast cancer which is mastectomy. It may have influence on the quality of life (QOL). So, this study was undertaken with the objective of evaluating the quality of life and related factors among patients operated for breast cancer.

Aims and Objectives-

1. To assess the quality of life of women who have undergone mastectomy.

2. To find association between quality of life and demographic variable.

\section{MATERIALS \& METHODS}

Evaluative approach with one group test design was used. Study was conducted on 30 subjects from Karad using convenient sampling technique. The data was collected by structured questionnaire. Data was analysed using descriptive and inferential statistics. The sample size estimation was also done at our conveniences.

\section{RESULTS}

Most of all women had severe complaints about quality of life, psychological changes, sociological behaviour, stress level, religious thinking and fear after undergoing mastectomy. There was no statistical association found between age, educational qualification, occupation, type of family, age of menarche and any of the quality of life parameters namely QOL, psychological changes, fear, sociological behaviour, stress levels and religious behaviour.

\section{CONCLUSION}

Majority of the women had severe complaints for quality of life, psychological changes, sociological behaviour, stress level, religious thinking and after undergoing mastectomy.

Most of the women had very severe complaints about fear after undergoing mastectomy.

\section{KEY WORDS}

Quality of Life, Mastectomy, Religious Thinking, Psychological Changes.

HOW TO CITE THIS ARTICLE: Bhosale TS, Shinde M, Patel R, et al. A study to assess the quality of life after mastectomy among women in a tertiary care hospital, Karad. J. Evolution Med. Dent. Sci. 2018;7(49):5273-5277, DOI: 10.14260/jemds/2018/1170

\section{BACKGROUND}

Breast cancer is the most common cancer in women. ${ }^{1,2,3}$ The incidence of breast cancer in India, as reported in the National Cancer Registry Program, Indian Council of Medical Research, varied from 23 to 32 per 100, 000 women. ${ }^{4}$

Breast is an emotional symbol of a woman's pride and personality, including sexuality, motherhood, self-image and self-esteem. Any threat to breast is to shake the very core of her mind and feminine orientation. ${ }^{5}$ The diagnosis of breast cancer generates more anxiety than any other cancer diagnosis. ${ }^{6}$ At the time of diagnosis patients experience uncertainty, confusion, and distress. Surgical options that include mastectomy and reconstruction, present unique

'Financial or Other Competing Interest': None.

Submission 24-10-2018, Peer Review 17-11-2018,

Acceptance 24-11-2018, Published 03-12-2018.

Corresponding Author:

Trupti S. Bhosale,

Statistician, Directorate of Research,

Krishna Institute of Medical Sciences,

Deemed To Be University, Karad,

Maharashtra, India.

E-mail: truptivp2010@gmail.com

DOI: $10.14260 /$ jemds/2018/1170 issues as the patient contemplates the advantage and disadvantage of each procedure. ${ }^{7}$

Surgical treatment is the most common treatment of breast cancer. ${ }^{8}$ The effect of breast cancer and its treatments such as mastectomy on a patient causes extreme mental stress leading to many emotional disorders like anxiety, tension, depression, grief, anger, hopelessness, helplessness, fear and a high degree of passivity, also psychological discomfort, especially mood disorders, and in general, its influence on the quality of life (QOL) which is greatly reduced after breast surgery.9,10 Patients after mastectomy also receive radiation therapy and/ or chemotherapy plus systemic hormonal therapy for breast cancer treatment depending on stage and oestrogen receptor status at diagnosis. Long term consequences of therapy include painful and often debilitating lymph oedema, due to surgery or radiation therapy consequently, these patients are engaged with cancer and its outcomes and effects for a long time.11

With respect to the components such as the increased incidence of breast cancer, the high level of impact of this disease on all aspects of people's lives, several complications of mastectomy, and adverse effects on the QOL, and similarly, with regard to the undeniable position of women at home and 
family and rapid transmission of disease consequences to the other members of the family. ${ }^{12}$

Therefore it is critical for health care professionals to become familiar with the impact of a breast cancer diagnosis and its treatment on patients QOL. ${ }^{11}$ So, this study was undertaken with objective to evaluate the quality of life and related factors among patients operated for breast cancer at a tertiary care hospital which would help the health care workers to organize different stress relieving activities for health promotion and improve the QOL of these patients.

\section{MATERIALS AND METHODS}

The target population for the study was post mastectomy women from tertiary care hospital. The study design was descriptive cross-sectional study. The convenient sampling technique was used for study.

Study was conducted on 30 post mastectomy women from tertiary care hospital. The structured questionnaire was used to assess quality of life of women after mastectomy. The sample size estimation was also done at conveniences.

Inclusion criteria were the women who were admitted in female surgical ward who undergone mastectomy and the women who were coming for follow up after mastectomy in cobalt unit of tertiary care hospital. The women who were admitted with other illness but had past history of mastectomy were also included. Exclusion criteria was the women who were admitted in female surgical ward with diagnosis other than mastectomy or not having past history of a mastectomy surgery

Data were collected, tabulated and analysed using SPSS version 20.0 with regard to objectives of the study using descriptive and Inferential Statistics. Frequency and percentage count were done for demographic variables and quality of life. Unpaired t test was done to find association between quality of life and demographic variable.

\section{RESULTS}

\begin{tabular}{|c|c|c|c|}
\hline $\begin{array}{l}\text { Sr. } \\
\text { No. }\end{array}$ & $\begin{array}{c}\text { Socio Demographic } \\
\text { Variables }\end{array}$ & No. & $\%$ \\
\hline \multirow{5}{*}{1} & \multicolumn{3}{|c|}{ Age } \\
\hline & $<30$ yrs. & 2 & 6.67 \\
\hline & $30-40$ yrs. & 9 & 30.00 \\
\hline & $41-50$ yrs. & 13 & 43.33 \\
\hline & $>50$ yrs. & 6 & 20.00 \\
\hline \multirow{5}{*}{2} & \multicolumn{3}{|c|}{ Educational Qualification } \\
\hline & Former & 6 & 20.00 \\
\hline & Primary & 10 & 33.33 \\
\hline & High School & 10 & 33.33 \\
\hline & Graduation \& Above & 4 & 13.33 \\
\hline \multirow{4}{*}{3} & \multicolumn{3}{|c|}{ Residential Area } \\
\hline & Urban & 7 & 23.33 \\
\hline & Peri Urban & 2 & 6.67 \\
\hline & Rural & 21 & 70.00 \\
\hline \multirow{6}{*}{4} & \multicolumn{3}{|c|}{ Occupation } \\
\hline & House Wife & 15 & 50.00 \\
\hline & Daily Wage Earner & 8 & 26.67 \\
\hline & Self Employed & 0 & 0.00 \\
\hline & Service & 0 & 0.00 \\
\hline & Labour & 7 & 23.33 \\
\hline \multirow{5}{*}{5} & \multicolumn{3}{|c|}{ Marital Status } \\
\hline & Married & 30 & 100.00 \\
\hline & Unmarried & 0 & 0.00 \\
\hline & Widowed & 0 & 0.00 \\
\hline & Divorce & 0 & 0.00 \\
\hline
\end{tabular}

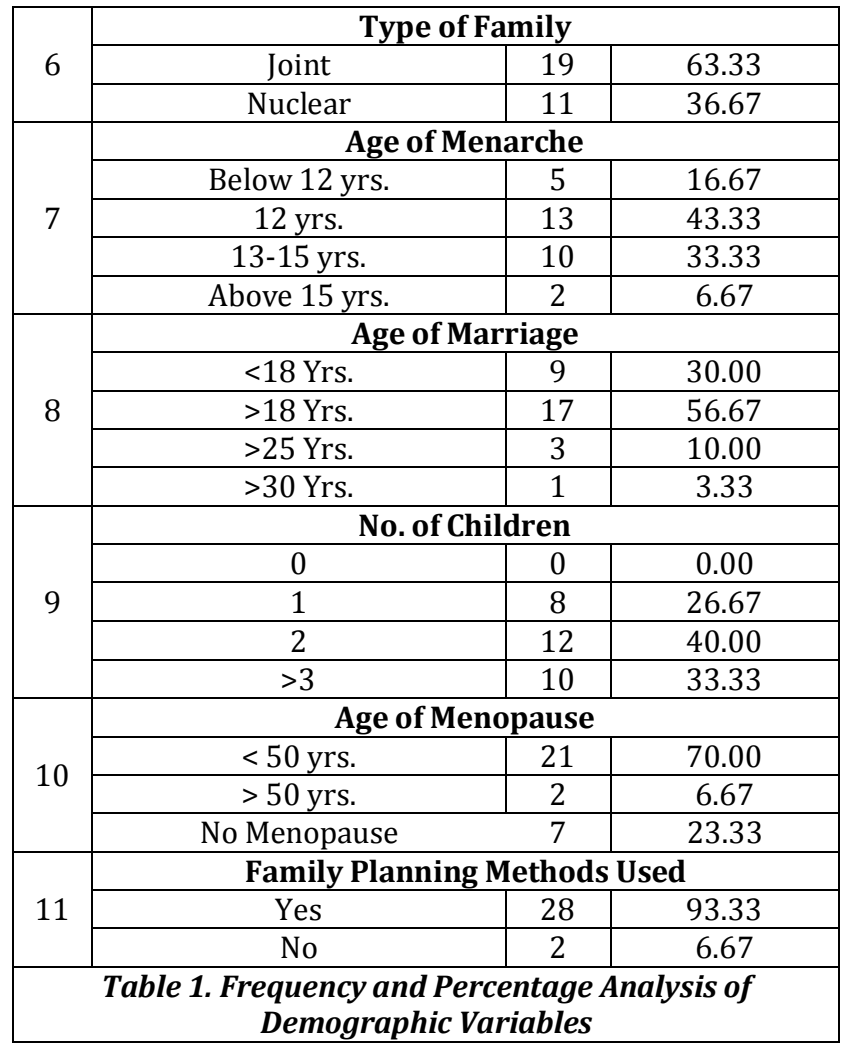

\section{Table 1 Depicts that}

- Most of $13(43.33 \%)$ respondent of women in tertiary care hospital, Karad who undergone Mastectomy were in the age group of 40-50 years, the remaining 9 (30\%) respondents who undergone Mastectomy were in the age group of 30-40 years. $6(20 \%)$ of the women patients were in the age group of $>50$ and only $2(6.67 \%)$ were in the age group of $<30$ years.

- $10(33.33 \%)$ of women who undergone Mastectomy had taken primary and high school education each. 6 (20\%) were illiterate. And 4(13.33\%) had done graduation and further education.

- Majority 21 (70\%) of women who undergone Mastectomy belonged to rural area. 7 (23.33\%) belonged to urban area. And 2(6.67\%) belonged to peri urban area.

- Maximum of women, who undergone Mastectomy was housewives $15(50 \%)$. Then $8(26.67 \%)$ were daily wage earners, 7 (25.33\%) were doing labour work.

- All of the women who undergone Mastectomy were married.

- $\quad$ Majority of women who undergone Mastectomy i.e. 19 (63.33\%) belonged to joint family and 6(36.67\%) belonged to nuclear family.

- Most of women who undergone Mastectomy i.e. 13 $(43.33 \%)$ had 12 years as age of menarche. $10(33.33 \%)$ had $13-15$ years as age of menarche. $5(16.67 \%)$ had $<12$ years age of menarche and $2(6.67 \%)$ had $>15$ years age of menarche.

- $\quad$ Maximum i.e. 17 (56.67\%) of women who undergone Mastectomy had marriage after completing 18 years. 9 $(30 \%)$ had marriage $<18$ years. $3(10 \%)$ had marriage after completing 25 years. Only 1 (3.33\%) had marriage after completing 30 years. 
- $12(40 \%)$ of women who undergone Mastectomy had 2 children. 10 (33.33\%) had more than 3 children. 8 $(26.67 \%)$ had only one child. No one belonged to category of having no child.

- Majority 21 (70\%) of women who undergone Mastectomy had menopause before completing 50 years of age. Only $2(6.67 \%)$ had menopause after completing 50 years of age and $7(23.33 \%)$ had not received menopause yet.

- $28(93.33 \%)$ of women who undergone Mastectomy use family planning methods and $2(6.67 \%)$ didn't use any family planning methods.

\begin{tabular}{|c|c|c|c|}
\hline \multirow{2}{*}{$\begin{array}{c}\text { Level of } \\
\text { Complaints }\end{array}$} & \multirow{2}{*}{ Score } & \multicolumn{2}{|c|}{ Level of Respondents } \\
\hline & & Frequency & Percentage \\
\hline \multicolumn{4}{|c|}{ Quality of Life } \\
\hline Mild & $1-7$ & 0 & 0 \\
\hline Moderate & $8-14$ & 6 & 20 \\
\hline Severe & $15-21$ & 23 & 76.67 \\
\hline Very Severe & $22-28$ & 1 & 3.33 \\
\hline \multicolumn{4}{|c|}{ Psychological Changes } \\
\hline Mild & $1-6$ & 0 & 0 \\
\hline Moderate & $7-12$ & 1 & 3.33 \\
\hline Severe & $13-18$ & 21 & 70 \\
\hline Very Severe & $19-24$ & 8 & 26.67 \\
\hline \multicolumn{4}{|l|}{ Fear Feeling } \\
\hline Mild & $1-3$ & 0 & 0 \\
\hline Moderate & $4-6$ & 5 & 16.67 \\
\hline Severe & $7-9$ & 11 & 36.67 \\
\hline Very Severe & $10-12$ & 14 & 46.67 \\
\hline \multicolumn{4}{|c|}{ Sociological Behaviour } \\
\hline Mild & $1-4$ & 0 & 0 \\
\hline Moderate & $5-8$ & 3 & 10 \\
\hline Severe & $9-12$ & 16 & 53.33 \\
\hline Very Severe & $13-16$ & 11 & 36.67 \\
\hline \multicolumn{4}{|l|}{ Stress Level } \\
\hline Mild & $1-12$ & 0 & 0 \\
\hline Moderate & $13-24$ & 0 & 0 \\
\hline Severe & $25-36$ & 20 & 66.67 \\
\hline Very Severe & $37-48$ & 10 & 33.33 \\
\hline \multicolumn{4}{|c|}{ Religious Thinking } \\
\hline Mild & $1-4$ & 0 & 0 \\
\hline Moderate & $5-8$ & 4 & 13.33 \\
\hline Severe & $9-12$ & 15 & 50 \\
\hline Very Severe & $13-16$ & 11 & 36.67 \\
\hline $\begin{array}{r}\text { Table 2. Cla } \\
\text { Mas }\end{array}$ & $\begin{array}{l}\text { cation o } \\
\text { my acce }\end{array}$ & who & $\begin{array}{l}\text { undergone } \\
\text { Life }\end{array}$ \\
\hline
\end{tabular}

In the table 2 it is noticeable that majority of women 23 (76.67\%) had severe complaints about quality of life, whereas $6(20 \%)$ of women had moderate complaints and 1 (3.33\%) of women had very severe level of complaints about quality of life. No one $0(0 \%)$ was having mild complaints.

Most of women $21(70 \%)$ had severe complaints about psychological changes, whereas $8(26.67 \%)$ of women had very severe level of complaints and $1(3.33 \%)$ of women had moderate complaints about psychological changes. No one $0(0 \%)$ was having mild complaints.

Majority of women $14(46.67 \%)$ had very severe complaints about fear feeling, whereas 11 (36.67\%) of women had severe level of complaints and $5(16.67 \%)$ of women had moderate complaints about fear feeling. No one $0(0 \%)$ was having mild complaints.
Maximum of women $16(53.33 \%)$ had severe complaints about social factors, whereas $11(36.67 \%)$ of women had very severe level of complaints and $3(10 \%)$ of women had moderate complaints about social factors. No one $0(0 \%)$ was having mild complaints.

Most of women 20(66.67\%) had severe complaints about stress, whereas $10(33.33 \%)$ of women had very severe level of complaints. No one $0(0 \%)$ was having mild and moderate complaints.

Maximum of women $15(50 \%)$ had severe complaints about religious thinking, whereas $11(36.67 \%)$ of women had very severe level of complaints and $4(13.33 \%)$ of women had moderate level of complaints about religious thinking. No one $0(0 \%)$ was having mild complaints.

Overall maximum women had severe complaints for quality of life, psychological changes, sociological behaviour, stress level, religious thinking and after undergoing mastectomy.

Overall maximum women had very severe complaints about fear feeling after undergoing mastectomy.

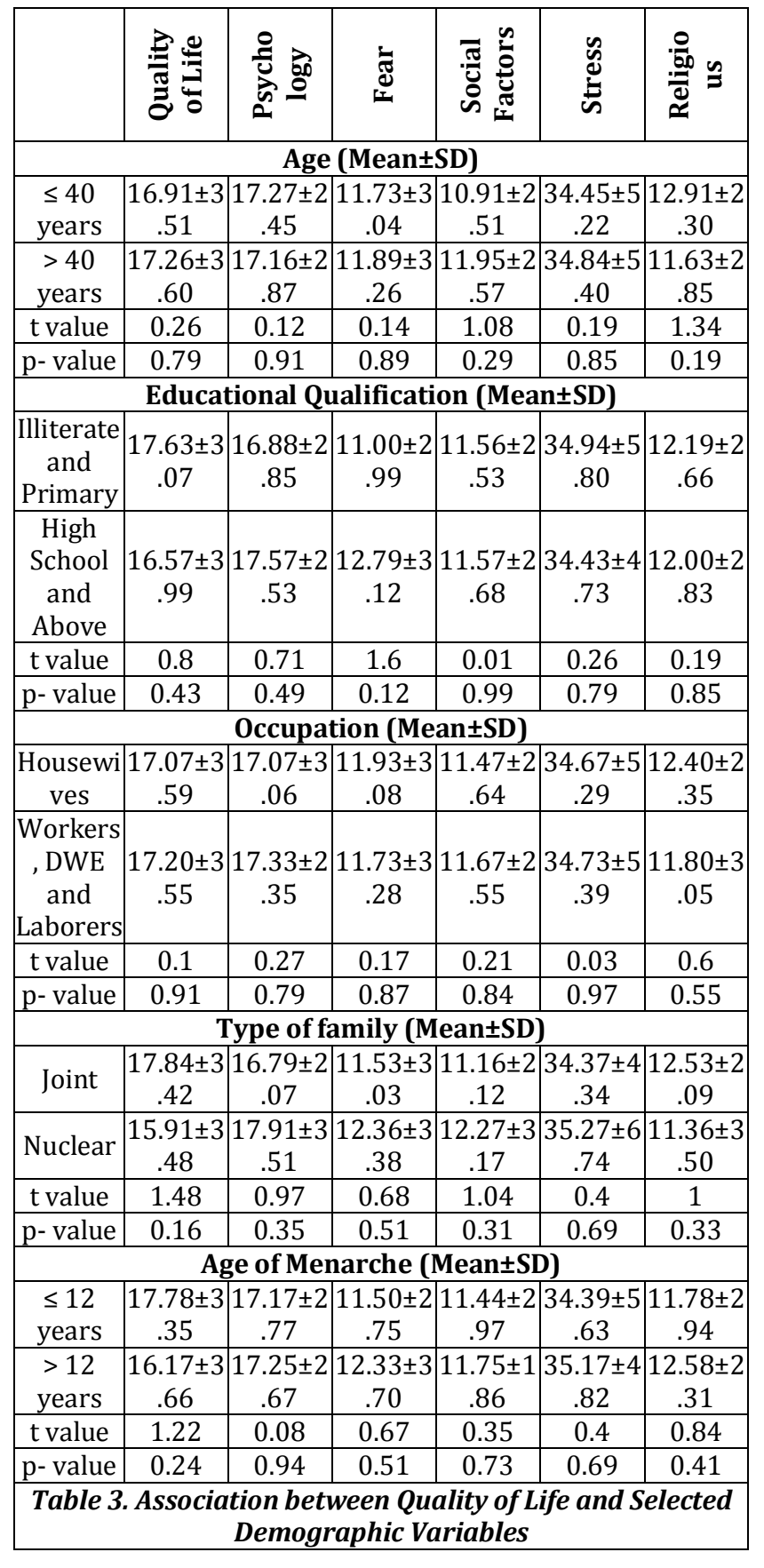




\section{Unpaired t test was used to test association between-}

1. Quality of life and age by dividing age into two groups as $\leq 40$ years and $>40$ years.

2. Quality of life and educational qualification by dividing age into two groups as illiterate and primary in one group and high school and above in another group.

3. Quality of life and occupation by dividing age into two groups as housewives and workers, DWE and laborers.

4. Quality of life and type of family by dividing age into two groups as joint family and nuclear family.

5. Quality of life and age of menarche by dividing age into two groups as $\leq 12$ years and $>12$ years.

Table 3 depicts that there was no statistical association found between age, educational qualification, occupation, type of family, age of menarche and any of the quality of life parameters namely QOL, psychological changes, fear feeling, sociological behaviour, stress levels and religious behaviour as all $\mathrm{p}>0.05$.

\section{DISCUSSION}

Many research studies have been conducted in National and International level to determine the quality of life after mastectomy among women.

In present study findings suggest that, $20 \%$ patients had quality of life as moderate, $76.67 \%$ patients had quality of life as severe and $3.33 \%$ patients had quality of life as very severe. Quality of life as perceived by the patients studied was good for $65 \%$ of patients, average for $12 \%$ of patients and poor for $23 \%$ of patients. ${ }^{4}$ In another study $61 \%$ patients had quality of life as good while $13 \%$ had average and $9 \%$ had poor quality of life. ${ }^{12}$

In present study, $3.33 \%$ patients had psychological changes as moderate, $70 \%$ patients had psychological changes as severe and $26.67 \%$ patients had psychological changes as very severe. Quality of psychological health was good for $31 \%$ of patients, average for $48 \%$ of patients and poor for $18 \%$ of patients ${ }^{4}$ while in another study it has been reported to be average for $55.5 \%$ of patients and good for $19.4 \%$ of patients while was poor for $25 \%$ of patients. ${ }^{12}$

The findings of the study show that the QOL of the majority of subjects was moderate.11 QOL of the majority of women with breast cancer who had undergone mastectomy was moderate at $56 \%{ }^{13}$ which was not consistent with the findings of this study as QOL of the majority of subjects $76.67 \%$ was severe. This finding was consistent with the result of the another study in which, it was found that QOL for the majority of the studied subjects $(87.5 \%)$ was lower than moderate level. ${ }^{14}$

In the present study, findings suggest that there was no statistical association found between age, educational qualification, occupation, type of family, age of menarche and any of the quality of life parameters namely QOL, psychological changes, fear feeling, sociological behaviour, stress levels and religious behaviour while there was significant association between occupational status and global quality of life.15,16

\section{CONCLUSION}

Most women had severe complaints for quality of life, psychological changes, sociological behaviour, stress level, religious thinking and after undergoing mastectomy.
Most women had very severe complaints about fear after undergoing mastectomy.

Therefore, it is suggested that health care workers receive the necessary training through academic courses and conduction of workshops to improve knowledge of the factors affecting the QOL. They should gain knowledge in areas such as proper management of patients, optimal management of problems, complications of the disease and its treatment, organize different stress relieving activities for health improvement, and finally, promotion of the QOL of the patients with cancer.

\section{ACKNOWLEDGEMENTS}

The authors would like to show their gratitude to Ms. Supriya Abadar and Ms. Ashy Mathew, final year GNM students for their sincere contribution to this study.

\section{REFERENCES}

[1] Ferlay J, Shin HR, Bray F, et al. Estimates of worldwide burden of cancer in 2008: GLOBOCAN 2008. Int J Cancer 2010;127(12):2893-917.

[2] Perry SH, Kowalski TH, Chang CH. QOL assessment in women with breast cancer: benefits, acceptability and utilization. Health Qual Life Outcomes 2007;5:24.

[3] Carlan G, Nigard H. Disease of women and obstetrics (Danforth 2008). Chapter 56. 10th edn. Philadelphia: Lippincott Williams \& Wilkins 2010: p. 1219-67.

[4] Annual Report. National Cancer Registry Program. Indian Council of Medical Research 2005: p. 68 http://ncrpindia.org/Report_NE_2005_06/pbcr2004_ 05/PreliminaryPages_PBCR2004_2005.pdf.

[5] Shastri A, Agarwal M, Patel H, et al. A study of quality of life among patients undergoing mastectomy for malignant breast lesions. Int Surg J 2017;4(11):363840.

[6] Dunn J, Steginga SK. Young Women's experiences of breast cancer: defining young and identifying concerns. Psychooncology 2000;9(2):137-46.

[7] Stefanek ME, Derogatis LP, Shaw A. Psychological distress among oncology outpatients. Prevalence and severity as measured with the Brief Symptom Inventory. Psychosomatics 1987;28(10):530-2, 537-9.

[8] Smeltzer SC, Bare BG. Bronner and Suddarth Text Book of medical surgical nursing. $9^{\text {th }}$ edn. Philadelphia: Lippincott 2000: p. 272, 297, 301.

[9] Kissane DW, Clarke DM, Lkin J, et al. Psychological morbidity and QOL in Australian women with earlystage of breast cancer: a cross-sectional survey. Med J Aust 1998;169(4):192-6.

[10] Shimozuma K, Ganz PA, Petersen L, et al. QOL in the first year after breast cancer surgery: rehabilitation needs and patterns of recovery. Breast Cancer Res Treat 1999;56(1):45-57.

[11] Engel J, Kerr J, Schlesinger-Raad A, et al. Predictors of quality of life of breast cancer patients. Acta Oncol 2003;42(7):710-8.

[12] Musarezaie A, Zargham-Boroujeni A. Quality of life and related factors among the women undergoing mastectomy. Iran J Nurs Midwifery Res 2015;20(2):287-91. 
[13] Agarwal P, Patel AK, Saxena A, et al. Assessment of quality of life after breast reconstructive surgery following mastectomy for carcinoma breast. J Surg Pak 2011;16(2):50-2.

[14] Fazel B, Tirgari N, Mokhber M, et al. The effect of mastectomy on mood and QOL in breast cancer patients. J Shahid Sadoughi Univ Med Sci Health Serv 2008;16:28-36.
[15] Nemati M, Alhani F, Zandshahri R. Iran: The First Congress of QOL in Tarbiat Modares University: QOL in the adolescence with cancer under chemotherapy referred to selected clinic of Tehran University of Medical Sciences, 2005: p. 25.

[16] Kannan K, Prashant KR, Rao JGS. Quality of life of women with breast cancer at a tertiary care hospital. Int J Biol Med Res 2011;2(4):1003-5. 